\title{
Visualization of Green's function anomalies for megathrust source in Nankai Trough by reciprocity method
}

\author{
Anatoly Petukhin ${ }^{1 *}$, Ken Miyakoshi ${ }^{1}$, Masato Tsurugi ${ }^{1}$, Hiroshi Kawase $^{2}$ and Katsuhiro Kamae ${ }^{3}$
}

\begin{abstract}
We used simulation by the reciprocity method to visualize the distribution of Green's function amplitudes in the source of a megathrust earthquake in the Nankai Trough and considered the effects of various areas (asperities or strong motion generation areas) on the simulated long-period ground motions at Konohana in the Osaka basin. We employed a fault source model proposed for an anticipated M9-class event in the Nankai Trough and the 3D Japan Intergrated Velocity Structure Model developed for simulations of long-period ground motions in Japan. Green's functions were calculated for about 1400 subsources by combining the finite-difference method and the reciprocity approach. Depths, strikes, and dips of subsources were adjusted to the shape of the upper boundary of the Philippine Sea plate. Ground motions with periods of 4-20 s were considered. The simulated distribution of peak amplitudes of Green's functions identified two strongly anomalous areas: (1) a large along-strike elongated area just south of the Kii Peninsula and (2) a parallel area closer to the trench. The elongation of the anomalies corresponded well with depth isolines at the top of the Philippine Sea plate. Postulating that plate shape influences simulated ground motions, we investigated the effect on Green's function amplitudes of phenomena related to plate shape: radiation pattern; variations of medium properties (e.g., velocity and density) at subsource depths; depth, strike, and dip; and the effect of soft sediments. We suggest that the cumulative effect on Green's function amplitudes of subsource radiation patterns, medium properties at subsource depth, reflection from crustal interfaces, and passage through soft sedimentary layers plays a critical role in the formation of amplitude anomalies. Analysis of waveforms and the time delay of peak amplitude demonstrate that large-amplitude waves of Green's functions in shallow parts of the plate boundary are composed mostly of surface waves.
\end{abstract}

Keywords: Megathrust earthquake, Source modeling, Green's function, Long-period ground motions, Reciprocity method, Nankai Trough

\section{Introduction}

The 2011 Tohoku earthquake $\left(M_{\mathrm{w}} 9\right)$ raised awareness of the dangers of future devastating earthquakes in nearby regions such as the Nankai Trough. The probability of a major earthquake occurring in the Nankai Trough has been estimated to be about $70 \%$ within the next 30 years (Headquarters for Earthquake Research Promotion 2013). Figure 1 shows the distribution of strong motion generation areas (SMGAs) according to several recent source models. Tsurugi et al. (2006) constructed a source model for Nankai-Tonankai earthquakes by

\footnotetext{
* Correspondence: anatolyp@geor.or.jp

${ }^{1}$ Geo-Research Institute, Otemae 2-1-2, Chuo-ku, Osaka 540-0008, Japan Full list of author information is available at the end of the article
}

revising the source model of the Central Disaster Management Council of Japan (Central Disaster Management Council of Japan 2003), which was constructed by inversion of historical distributions of seismic intensity. Morikawa et al. (2013) proposed and simulated several source models with quasi-random distributions of SMGAs. Figure 1 also shows areas of large slip derived from waveform inversion for the 1944 Tonankai earthquake according to the Headquarters for Earthquake Research Promotion (Headquarters for Earthquake Research Promotion 2009) and for the 1946 Nankai earthquake (Kagawa et al. 2012).

Knowledge of the locations of SMGAs and asperities is important in earthquake source modeling. By waveform inversion, Yamanaka and Kikuchi (2004) identified
Springer

(c) 2016 Petukhin et al. Open Access This article is distributed under the terms of the Creative Commons Attribution 4.0 International License (http://creativecommons.org/licenses/by/4.0/), which permits unrestricted use, distribution, and reproduction in any medium, provided you give appropriate credit to the original author(s) and the source, provide a link to the Creative Commons license, and indicate if changes were made. 


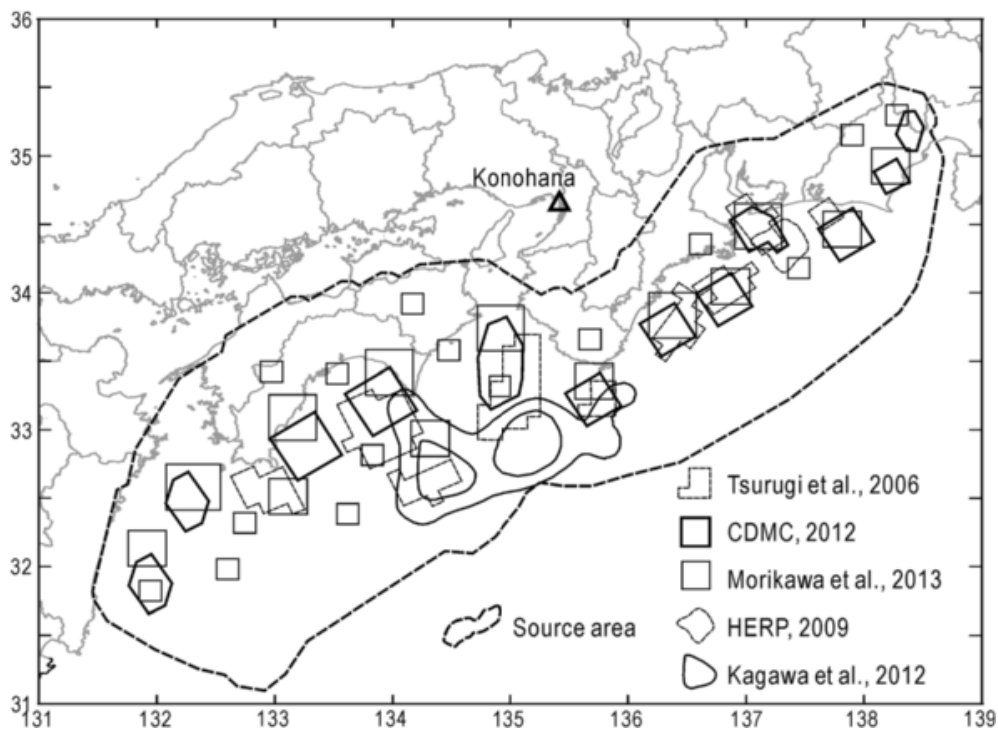

Fig. 1 Likely source area for anticipated M9 earthquake in the Nankai Trough. Heavy dashed line indicates source area proposed by Central Disaster Management Council of Japan (2012) and used in this study. SMGAs proposed for different source models in previous studies are shown for reference

asperities along the subduction zone off northeastern Japan and showed that there have been repeated ruptures on some asperities in the Tohoku region. They concluded that the asperities for future earthquakes are likely to be in areas where slip was large during previous earthquakes. From another side, it is important to know the largest likely ground motion in areas of critical infrastructure (e.g., nuclear power plants, high-rise buildings), which is dependent on the distribution of SMGAs.

Estimation of the null-space in the source inversion process is also important. This analysis usually occurs after inversion (frequently in the background): areas of large slip are individually tested to determine whether or not they produce waveforms of greater amplitude than background noise or inversion misfit (e.g., Sekiguchi et al. 2000; Kakehi 2004; Yoshida et al. 2011). A straightforward approach requires estimation of waveform amplitudes from every subsource to constrain slip for subsources that have small waveform amplitudes at all observation sites (e.g., Poiata et al. 2012).

Here we examined how the distribution of SMGAs can affect the amplitude of long-period ground motions at important sites (e.g., the megacity of Osaka). When the effect of seismic activity at SMGAs on ground motion at a particular location is tested by separate simulations for each SMGA, the effects of SMGA location and rupture propagation (e.g., the directivity effect) are mixed. In this study, we separated the effect of SMGA location from the effect of rupture propagation and calculated the distribution of peak amplitudes of Green's functions (GFs) at our target site, Konohana (OSKH02) in the center of the Osaka basin. We used the reciprocity theorem (e.g., Aki and Richards 1980) for our GF calculations in a complex 3D velocity structure model. This theorem states that when the locations and orientations of a seismic source and observation point are swapped, the same elastic response is observed. This procedure greatly reduced computational time, which allowed us to complete a detailed study in a reasonable time.

\section{Source model}

We used the source model of Central Disaster Management Council of Japan (2012), which includes 1404 subsources on a $10-\mathrm{km}$ mesh in area bounded by a dashed line in Fig. 1. To calculate GFs for this study, we placed the subsources at the upper boundary of the subducting Philippine Sea plate and used the 3D Japan Integrated Velocity Structure Model (JIVSM) of Koketsu et al. (2012).

In applications of the finite-difference method (FDM), it is difficult to place a large number of subsources exactly on a curved plate boundary. Moreover, because that boundary separates media with different properties, a point source represented by a cubic cell of $2 \times 2 \times 2$ grid sizes (Graves 1996) may have nodes unintentionally assigned to different media. This kind of source settings may need additional treatment and testing. To avoid possible ambiguity related to artificial rotational forces, for example, we ensured that subsources were within a homogeneous medium by placing them two grid spaces (about $1.5 \mathrm{~km}$ ) above the plate boundary. Strike and dip angles were also adjusted according to the shape of the 
upper surface of the subducting plate. The obtained distributions of subsource depth, strike, and dip are shown in Fig. 2.

\section{Calculation of Green's functions}

To calculate GFs, we used the 3D FDM. This is an accurate method, but time-consuming because of the large number of subsources used for source inversion and forward ground-motion simulation. For example, inversion of the 1946 Nankai earthquake by Kagawa et al. (2012) involved 144 subsources, in effect, 288 subsources considering the two perpendicular rake angles used for inversion. Thus, the Kagawa et al. (2012) and Central Disaster Management Council of Japan (2012) models would require 288 and 2808 runs, respectively, of the 3D FDM simulation. To reduce our simulation time, we employed the reciprocity method, described in detail by Eisner and Clayton (2001) and Graves and Wald (2001), which calculates responses to three single forces in the NS, EW, and depth directions at the target site. The calculated waveforms for each subsource are then manipulated using the moment tensor contributions at the desired source location for each of the reciprocal force calculation, to replicate the responses to the subsource moment tensor at the target site. Thus, application of the reciprocity method to the Central Disaster Management Council of Japan (2012) model means that only three FDM simulations (rather than 2808) per target site are necessary to calculate GFs from all subsources.

First, we verified the validity of the $3 \mathrm{D}$ reciprocity method for calculation of GFs in the Nankai Trough by simulating three point sources in different parts of the trough (locations shown in Fig. 3). The simulated depths, dips, and strikes at these three points were similar to those of the CDMC model (Fig. 2). We used a dummy value for seismic moment $M_{0}=10^{20} \mathrm{Nm}$, a short rise time of $T_{\text {rise }}=2 \mathrm{~s}$, and a triangular source-time function, as is widely used in multi-time-window source inversions. The rake angle used in the simulations was $90^{\circ}$. Note that the specification of dip, strike, and rake for reciprocity simulations is not required at the FDM simulation stage; instead they are specified at the stage of manipulation of the moment tensor, which increases processing speed and is an additional advantage of the reciprocity method. Considering the uncertainty of the 3D velocity structure model in comparison to the real structure, comparisons of the waveforms of forward and reciprocal simulations for EW and NS components (Fig. 3) show little difference.

For our 3D velocity structure model, we used the wellcalibrated and waveform tested (Petukhin et al. 2012) JIVSM model of Koketsu et al. (2012). This model is designed to deal with both sedimentary basins and crustal structures. It incorporates the Osaka basin model of
Kagawa et al. (2004) and the Philippine Sea subduction plate interface and accretionary prism models of Baba et al. (2006), which together make it well-suited for earthquake modeling.

We carried out our 3D simulations by using the conventional staggered grid, fourth-order FDM scheme (Graves 1996) with a nonuniform grid size (Pitarka 1999). This approach simplifies the simulation of a double-couple seismic source and reduces computation cost (memory and time) for models with low-velocity sedimentary layers. The shortest wave period considered in the simulations was $4.2 \mathrm{~s}$. The lowest shear-wave velocity in the JIVSM model, that defines combination of grid size and wave period, was $350 \mathrm{~m} / \mathrm{s}$ (in the uppermost soft sedimentary layer in the Osaka basin having $\sim 500 \mathrm{~m}$ depth). The horizontal grid size for FDM simulations was $300 \mathrm{~m}$ (five grids for the shortest wavelength). A nonuniform grid size was used in the depth direction. For sedimentary layers shallower than $4200 \mathrm{~m}$ (the deepest level of soft oceanic sediments), a vertical grid spacing of $220 \mathrm{~m}$ was used; from 4200 to $9200 \mathrm{~m}$ depth (hard oceanic sediments), grid spacing was $440 \mathrm{~m}$; and at greater depths, it was $880 \mathrm{~m}$. The maximum depth of the calculation volume was $70 \mathrm{~km}$, and we used 10,350 time steps at intervals of $0.0145 \mathrm{~s}$.

\section{Results}

The distribution of peak amplitudes of calculated GFs is shown in Fig. 4 for rake angles of $0^{\circ}$ and $90^{\circ}$ for transverse and radial components, respectively; the distributions of subsource location, depth, strike, and dip are shown in Fig. 2. Similarly to the validity test of the application of the reciprocity method in the Nankai Trough (discussed above), we used a triangular source-time function, a rise time of $T_{\text {rise }}=2 \mathrm{~s}$, and a seismic moment of $M_{0}=10^{20} \mathrm{Nm}$ for all subsources. Ground-motion periods of 4.2-20 s were considered. For convenience, peak GF amplitudes were normalized to a maximum value of 20. The distribution of peak amplitudes of GFs was markedly irregular. Two areas showed anomalously large amplitudes (Fig. 4): a large area elongated along the plate strike just south of the Kii Peninsula for transverse component for rake $=0^{\circ}$ (anomaly 1 ) and for radial component for rake $=90^{\circ}$ (anomaly 2) and a large area off the Kii Peninsula, trenchward of anomalies 1 and 2 , for radial component for rake $=90^{\circ}$ (anomaly 3). Although GF amplitudes would normally be expected to decrease with increasing distance from the source, they anomalously increased with increasing distance perpendicular to the trench axis. Figure 5 shows example transverse and radial waveforms for a line perpendicular to the trench axis.

The elongations of both anomalies correspond well with iso-depth lines on the upper surface of the Philippine Sea 

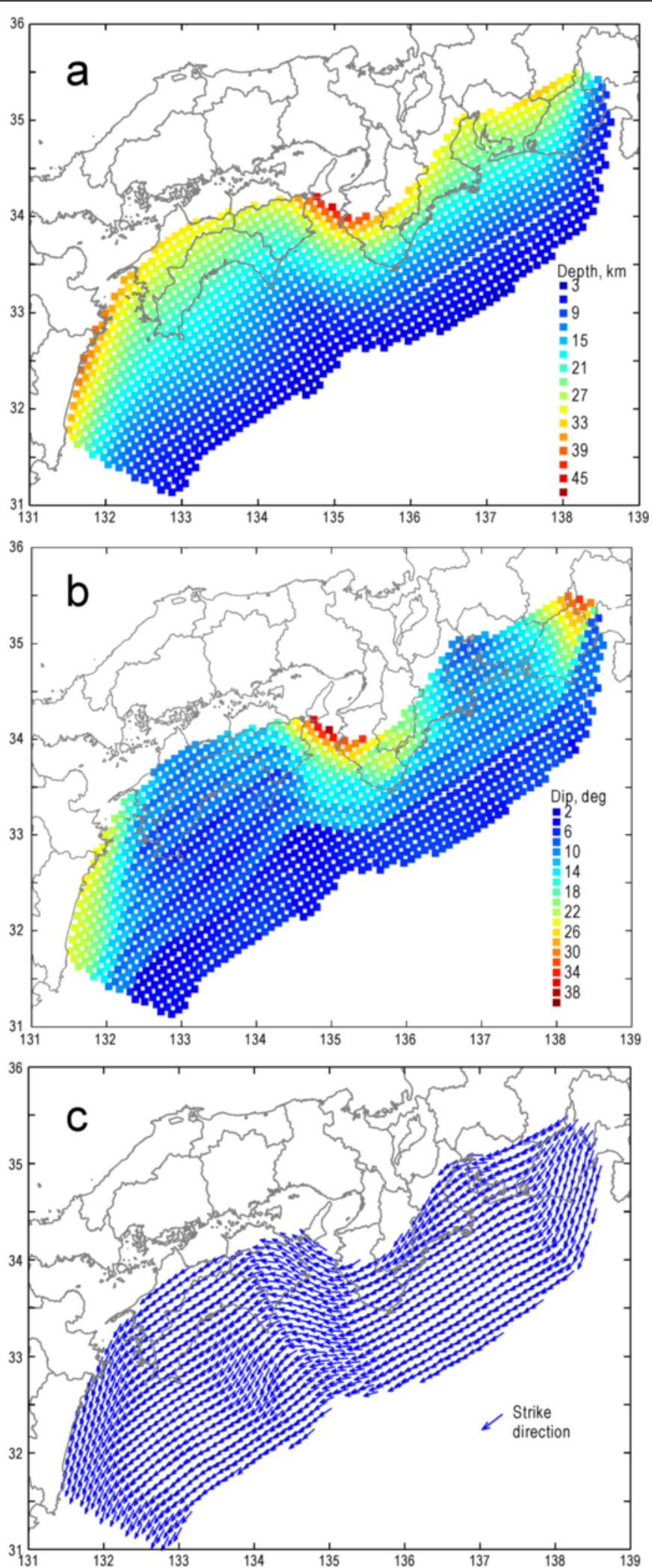

Fig. 2 Distributions of source parameters. Subsource (a) depth, (b) dip, and (c) strike 


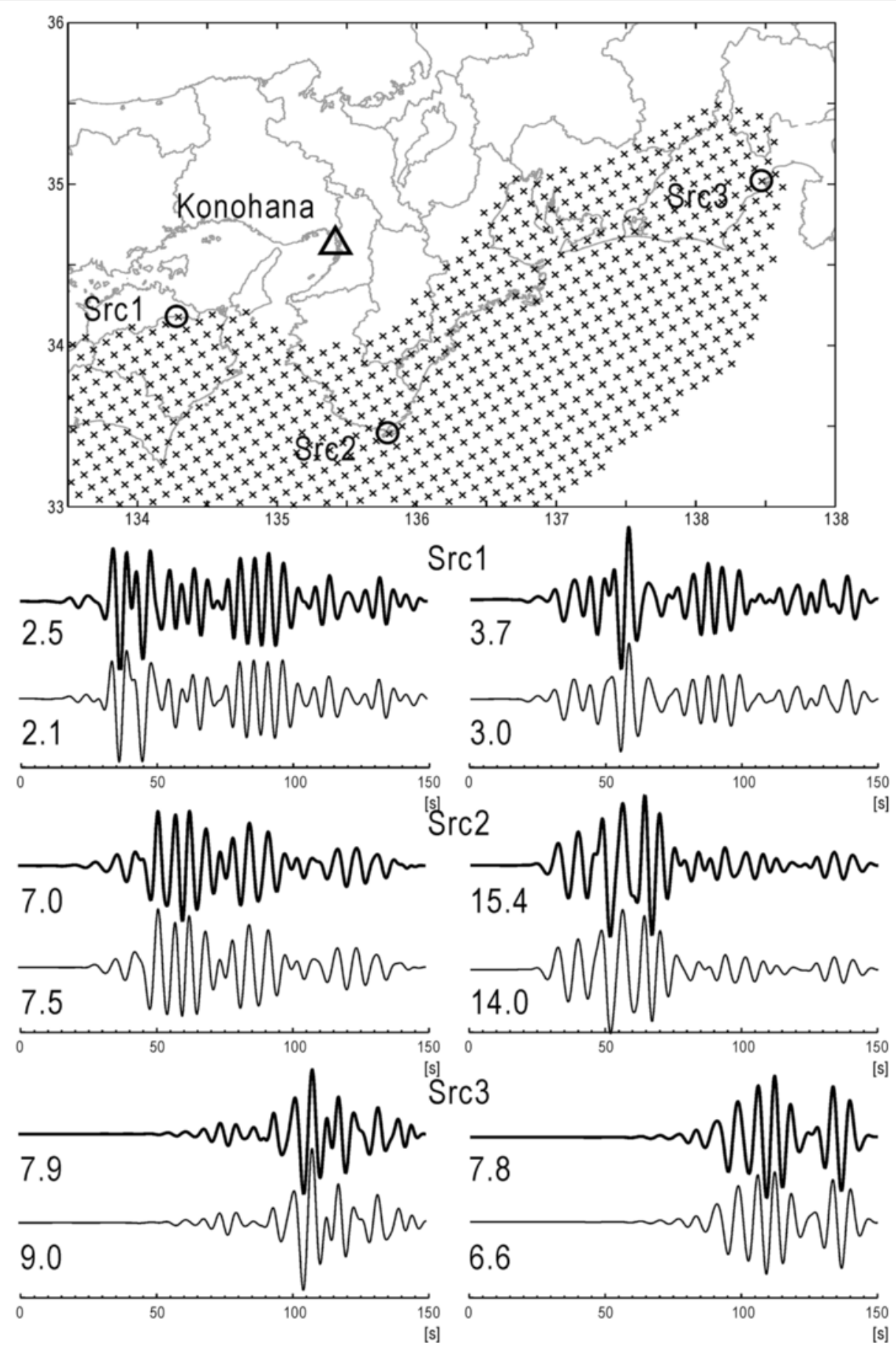

Fig. 3 Validation of the reciprocity approach. Comparison of reciprocal waveforms (thick lines) and forward simulated waveforms (thin lines) for EW (left) and NS (right) components for point sources Src1, Src2, and Src3, and for JIVSM model. Numbers at the left of each trace are normalized peak amplitudes

plate (compare Figs. 2a and 4), while target site Konohana is located on perpendicular to these isolines. For this reason, we speculate that plate shape may have a critical effect on simulated ground motions because of the cumulative effect of subsource radiation patterns and the distributions of strike and dip.
Effects of wave generation and propagation on GF amplitudes

There are six factors that may contribute to the observed GF amplitudes: source distance, source mechanism, generation of surface waves, seismic potency and seismic impedance at the source location, oceanic sediments in 

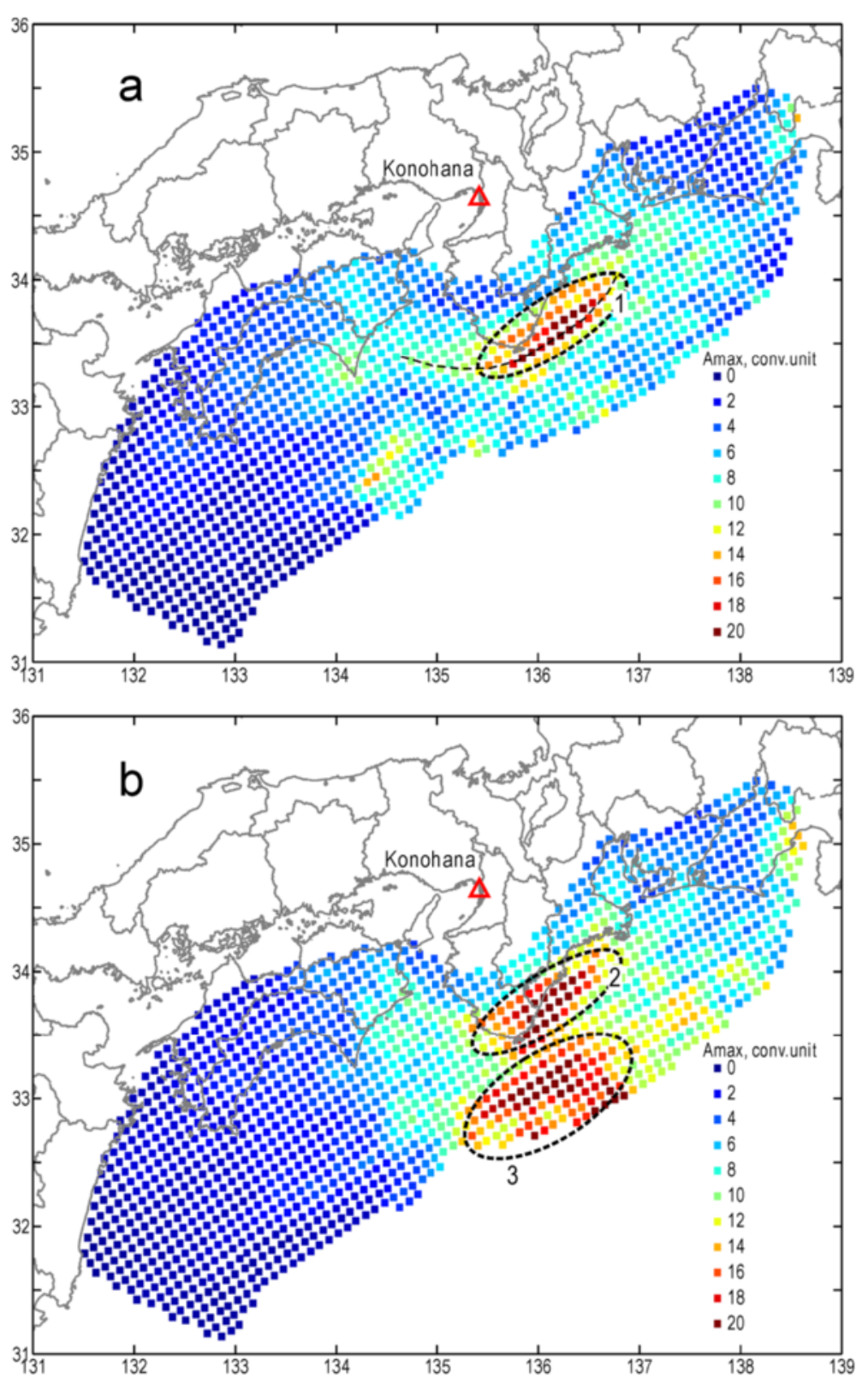

Fig. 4 Results of FDM simulation of GFs by using reciprocity theory and JIVSM model. Distributions of peak amplitudes for (a) transverse component for rake $=0^{\circ}$ and (b) radial component for rake $=90^{\circ}$. Peak GF amplitudes for both plots were normalized to a maximum value of 20

the accretionary prism, and basin sediments (Osaka basin) at the target site. Below, we analyze each of these factors.

\section{Source distance}

GF amplitudes are expected to decrease with increasing distance from the source (approximately proportional to $1 / R$ for body waves and $1 / R^{0.5}$ for surface waves, where $R$ is the distance from the source). This is roughly the case for subsources southwest of the target site, along the strike of the subducting plate (Fig. 4). In contrast, for subsources progressively farther southeast of the target site, this regular decrease of amplitude due to geometric spreading is not apparent. Other effects, that are enumerated above and will be discussed later, overlap with distance attenuation effect and results in a complicated distance dependence of amplitudes.

\section{Source mechanism}

To test the effect of source mechanism on GF amplitudes, we considered the amplitude distribution of $S$-waves from subsources in an infinite uniform medium according to the Aki and Richards (1980; their equation 4.33) as shown in Fig. 6. In contrast to the distribution of GF amplitudes shown in Fig. 4, the highest amplitudes are in areas of 

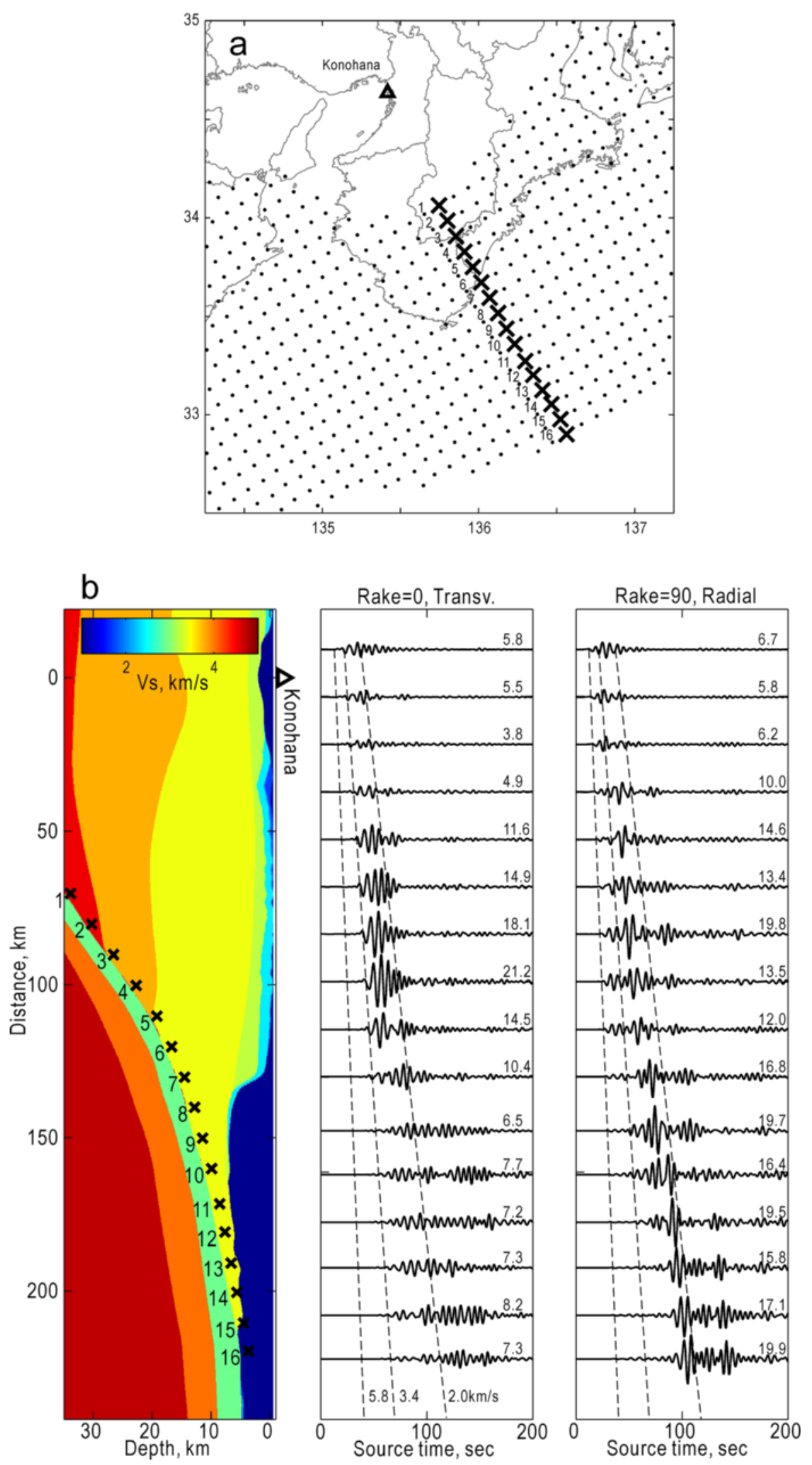

Fig. 5 (See legend on next page.) 
(See figure on previous page.)

Fig. 5 Examples of GF waveforms for subsources along a line perpendicular to the trench axis and JIVSM model. a Map showing location of Konohana (triangle) and subsources. Points on the map are all model subsources, and numbered crosses are subsources selected for waveform examples here and below. $\mathbf{b}$ Cross section of S-wave velocity structure and location of subsources (left); transverse component waveforms for rake $=0^{\circ}$ (center); radial component waveforms for rake $=90^{\circ}$ (right). Numbers at the right of each waveform are normalized peak amplitudes. Dashed lines indicate arrival of waves propagating with velocities $5.8,3.4$, and $2.0 \mathrm{~km} / \mathrm{s}$, which correspond approximately to $P$-waves, $S$-waves, and surface waves, respectively

steeper dip closer to the target site, and low to medium amplitudes are in the areas of anomalies 1 and 3 . We concluded from these results that the source mechanism alone cannot produce the simulated anomalies.

\section{Source depth distribution: generation of surface waves, seismic potency, and seismic impedance}

Shallow subsources generate large-amplitude surface waves that may result in GF amplitudes at the target site being larger because of the reduced effect of geometric spreading. Amplitudes of generated surface waves are proportional to amplitude of eigenfunctions, which in general increase both with decreasing of depth and with decreasing of velocity values at shallow depths. From another side, for a given seismic moment, the effects of seismic potency (Ben-Zion 2001) and seismic impedance at a source location are depth dependent. In order to evaluate the combined effect of these phenomena, we ran simulations with a $1 \mathrm{D}$ velocity structure (Figs. 7 and 8) that is equivalent to the onshore crustal velocity structure of the JIVSM model.

For the transverse component for rake $=0^{\circ}$, GF amplitudes were small for both deep and shallow subsources, but were clearly larger at intermediate depths (Fig. 7a), which is in good agreement with anomaly 1 (Fig. 4a). The larger amplitude waves of the transverse component should be surface Love waves or body $S$-waves. Amplitudes of Love waves are described by Aki and Richards (1980; their equations 7.148 and 7.149). For shallow subsources, Love wave amplitudes can be small because the terms related to small polar angles approach zero (true for subsources aligned on the perpendicular to the trench axis) due to the small horizontal moment tensor components for dip $\sim 0^{\circ}$ and rake $=0^{\circ}$ and the small depth derivatives of eigenfunctions of Love waves for lower modes at shallow depths.

For body waves, the effect of seismic potency at shallow depth, which increases amplitudes, may be smaller than the effect of the source radiation pattern, which decreases amplitudes for shallow subsources. Consequently, GF amplitudes for the transverse component were smaller at shallower depths and increased with increasing depth owing to the effect of the source radiation pattern (Fig. 7a). These interpretations are supported by example waveforms (Fig. 8); large-amplitude segment of transverse components correspond to large-amplitude $S$-waves (note waveforms for subsources numbered 6-12 in Fig. 8).

For the radial component for rake $=90^{\circ}$ (Fig. 7b), at first glance, the distribution of peak GF amplitudes is consistent with our original assumption for surface-wave generation; that is, amplitudes are large for shallow subsources and decrease with increasing depth. On the contrary, if we refer to Aki and Richards (1980; their equations 7.150 and 7.151), we see that although the eigenfunctions of Rayleigh waves and their derivatives are not zero at zero depth, all terms of equations 7.150 and 7.151 vanish due to the vanishing of terms related to the small polar angle in the direction perpendicular to the trench axis and the small moment tensor components $M_{x x}, M_{x z}$, and $M_{z z}$ for dip $\sim 0^{\circ}$ and rake $=90^{\circ}$. For this reason, we rejected the generation of Rayleigh waves as an explanation for anomaly 3 (Fig. 4).

On the other hand, the shape of the large-amplitude area in Fig. $7 \mathrm{~b}$ corresponds very well with the shallow subsource area (normalized amplitudes around 4) in Fig. $6 \mathrm{~b}$, which reflects the effect of the radiation pattern of $S V$-waves. Although the effect of the radiation pattern for shallow subsources alone cannot explain the large shallow anomaly in Fig. 7b, it can explain it if combined with the effect of greater seismic potency at shallow depth. Example waveforms shown in Fig. 8 confirm this interpretation: large-amplitude waves for the radial component for rake $=90^{\circ}$ from shallow subsources propagate at $S$-wave velocities.

However, despite the above investigation and analysis, an important question about the effect of seismic potency and seismic impedance at the source location remains unanswered. Namely, can these effects compensate the effect of the source radiation pattern or not? This question is considered in detail below, after our discussion of the effects on GF amplitudes of sedimentary layers in the accretionary prism and in the onshore basin.

\section{Oceanic sediments (accretionary prism) and basin sediments at the target site (Osaka basin)}

To test the effect of sedimentary layers on GF amplitudes, we ran simulations with a velocity structure model without sedimentary layers $\left(V_{S} \leq 2.4 \mathrm{~km} / \mathrm{s}\right)$ and compared the results with those obtained with the JIVSM model. Figure 9 shows the distributions of GF 

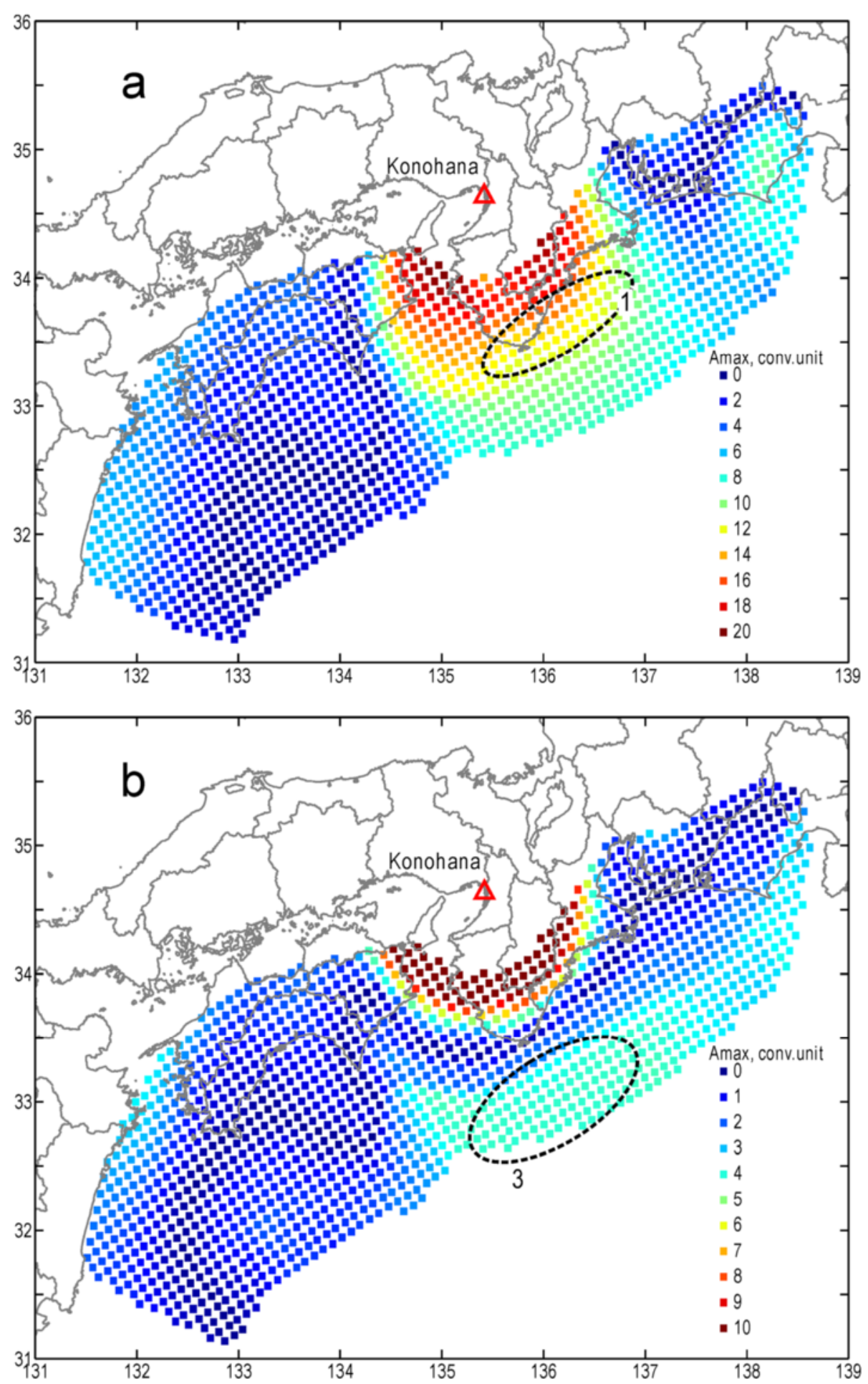

Fig. 6 Distribution of simulated peak GF amplitudes for subsources in an infinite uniform medium. a Transverse component for rake $=0^{\circ}$ and (b) radial component for rake $=90^{\circ}$. Dashed ellipses indicate locations of anomalies 1 and 3 shown in Fig. 4

amplitudes for simulations without sedimentary layers, and Fig. 10 shows some example waveforms. The cross section of the velocity structure shown in Fig. 10 can be compared with the cross section of the JIVSM model shown in Fig. 5. Because of the similarity of the 1D velocity structure model (cross section in Fig. 8) and the velocity structure without sedimentary layers (cross section in Fig. 10), the simulation results for the two 

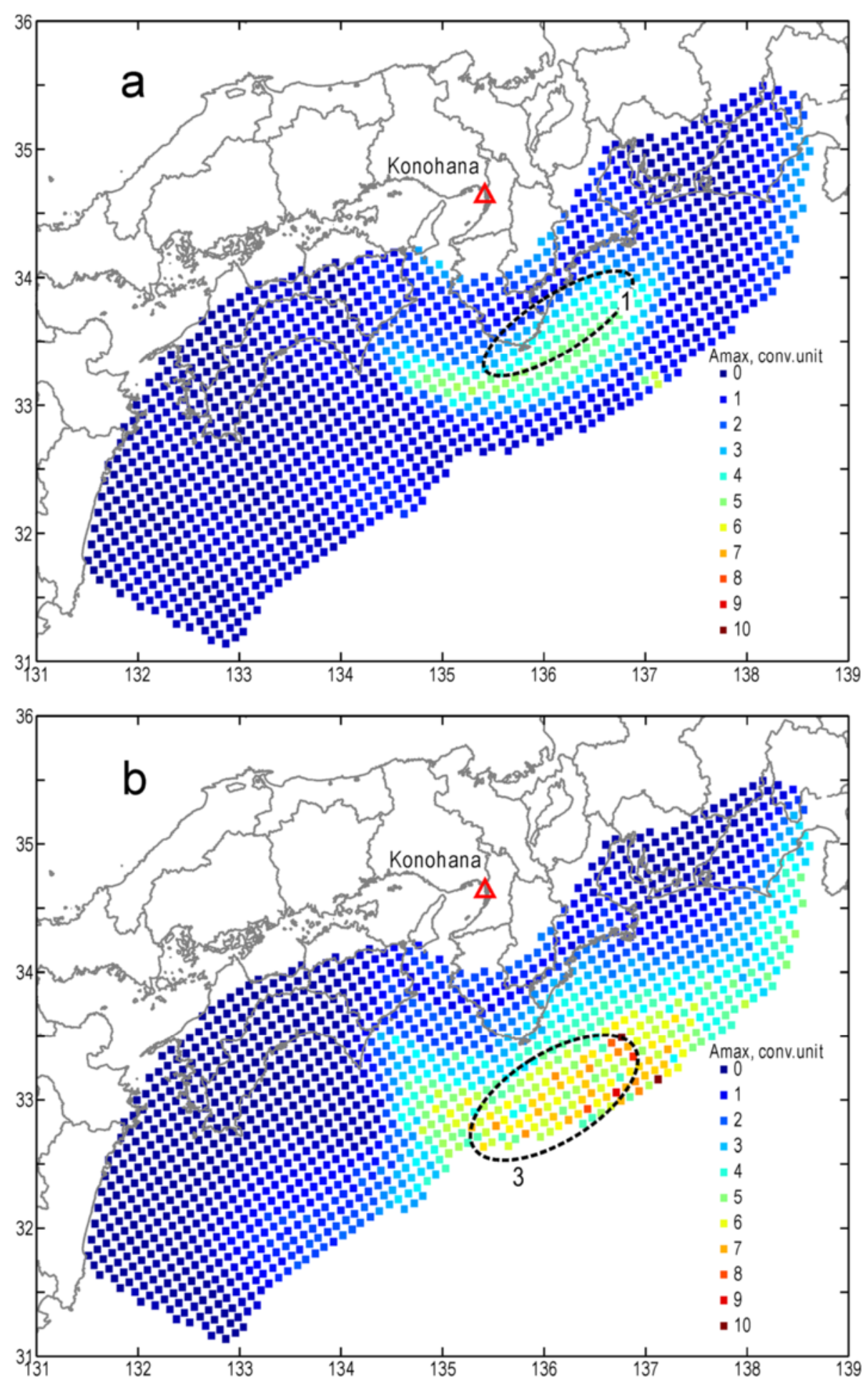

Fig. 7 Distribution of simulated peak GF amplitudes for subsources in a 1D velocity structure. a Transverse component for rake $=0^{\circ}$ and (b) radial component for rake $=90^{\circ}$. Velocity structure consists of four horizontal layers with velocities corresponding to the upper mantle, lower crust, upper crust, and seismic basement of the JIVSM model. Depths and S-wave velocities of layers are shown in the cross section of Fig. 8. Other annotations as in Fig. 6 


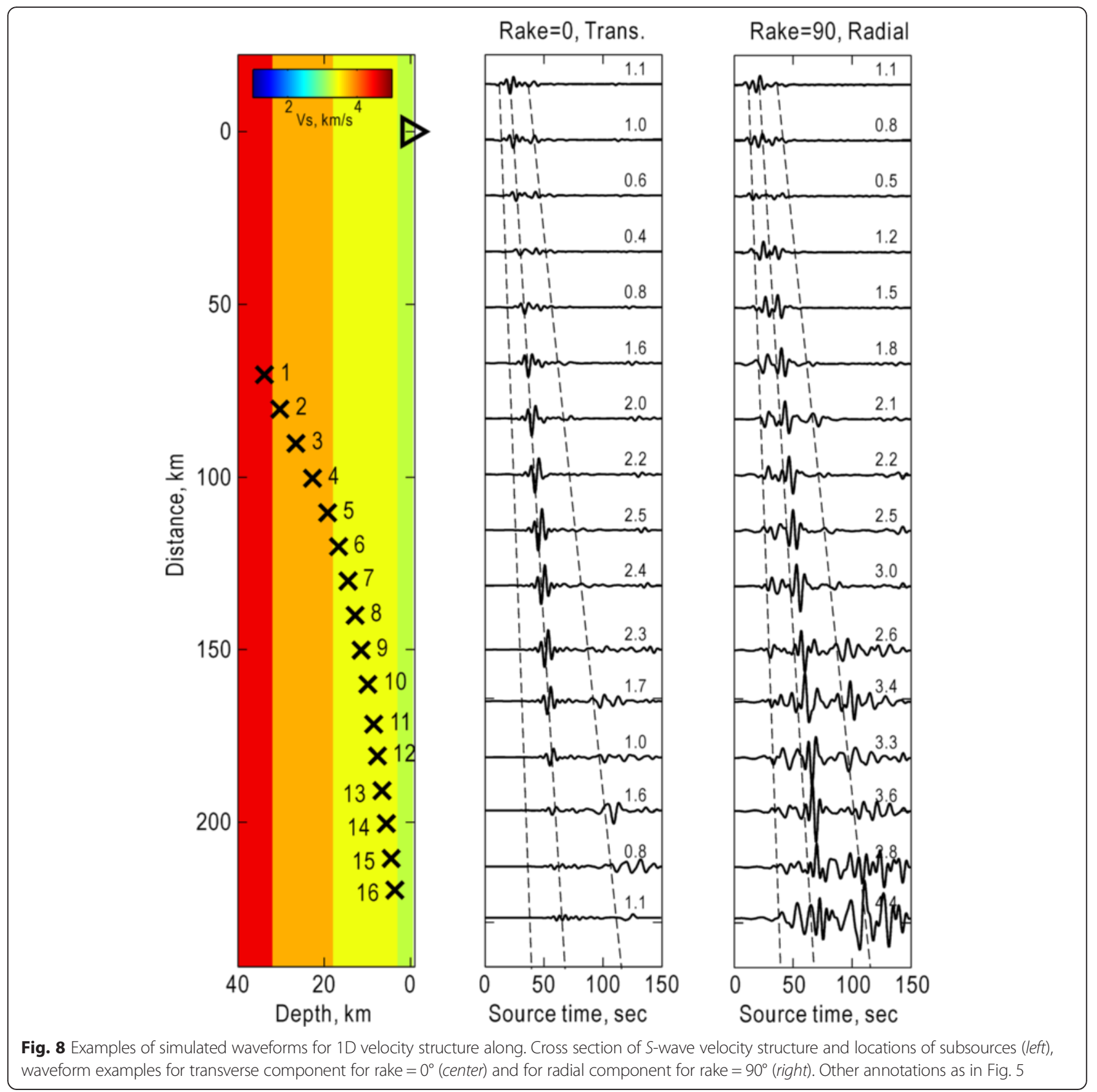

models are similar (compare Figs. 7 and 9). Both show two anomalies, one for the transverse component for rake $=0^{\circ}$ at intermediate depths (anomaly 1), and another for the radial component for rake $=90^{\circ}$ at shallow depths (anomaly 3 ). The previously identified anomaly 2 for the radial component at intermediate depths is not evident in the results of either simulation. Anomaly 2 appears only when the sedimentary layers of the Osaka basin are included in the velocity structure (i.e., when the JIVSM model is used).

Close examination of the transverse component waveforms corresponding to anomaly 1 (subsources numbered
5-9 in Fig. 5) reveals noticeable dispersion, which is unexpected for waves propagating at $S$-wave velocities. Characteristic for surface waves dispersion in the Osaka basin may arise from the generation of basin waves by incident $S$-waves. Similar dispersion is not evident for the radial component. However, the predominant wave period for the radial component is $6.2-6.7 \mathrm{~s}$, which is similar to that of the transverse component (6.0-6.7 s), and is also similar to the predominant wave period observed during the 2004 off Kii Peninsula earthquake $\left(M_{\mathrm{w}}\right.$ 7.4; e.g., Miyake and Koketsu, 2005). Miyakoshi et al. (2013) demonstrated that the generation of basin waves (Love and Rayleigh 

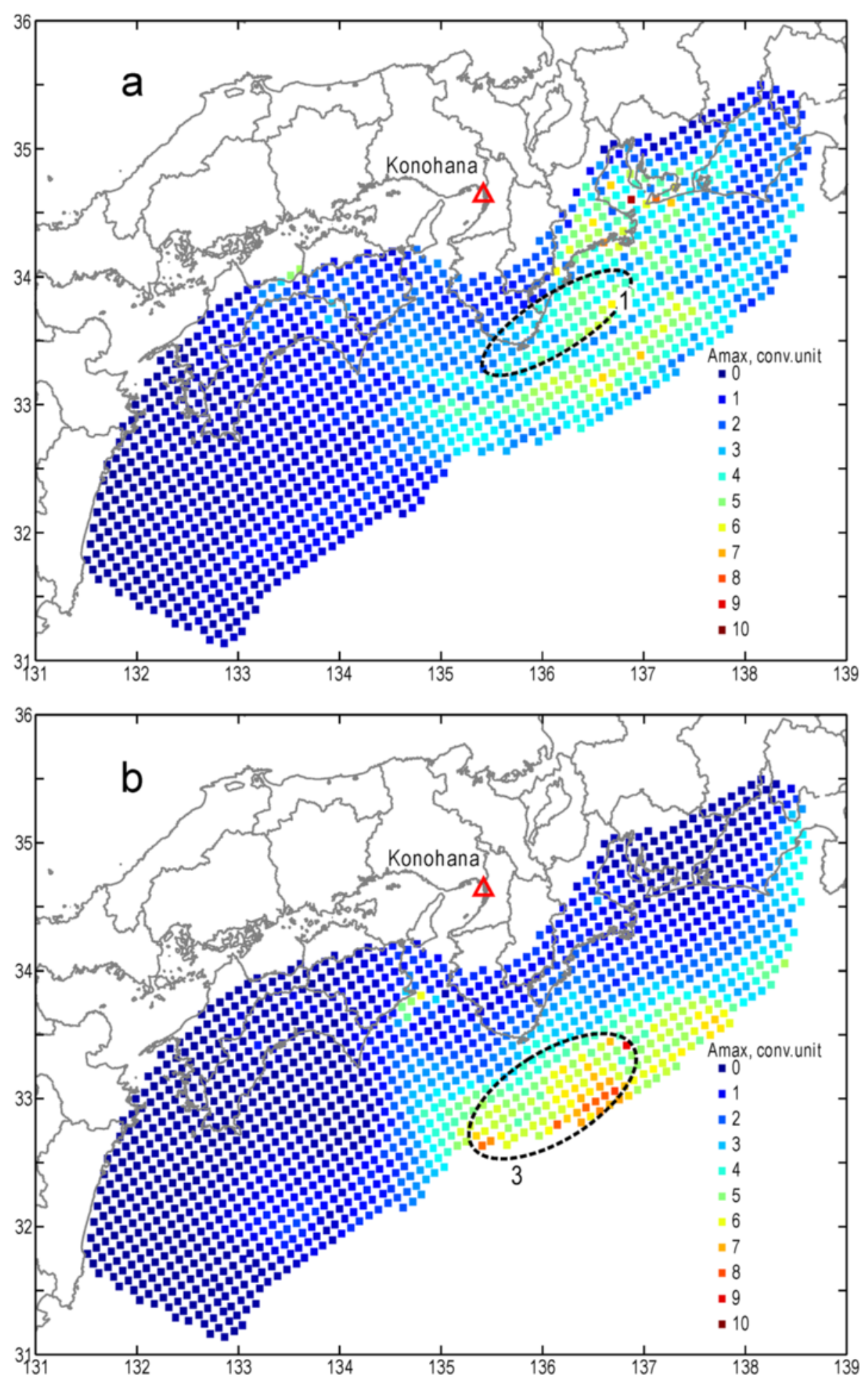

Fig. 9 Distribution of simulated peak GF amplitudes for velocity structure without sediment layers. a Transverse component for rake $=0^{\circ}$ and (b) radial component for rake $=90^{\circ}$. Waveforms here and in Fig. 10 were simulated by FDM using the reciprocity method and the JIVSM velocity structure model, but with layers for which $V_{S}<2.4 \mathrm{~km} / \mathrm{s}$ were replaced by layers with $V_{S}=2.4 \mathrm{~km} / \mathrm{s}$. S-wave velocity cross section is shown in Fig. 10. Other annotations as in Fig. 6 


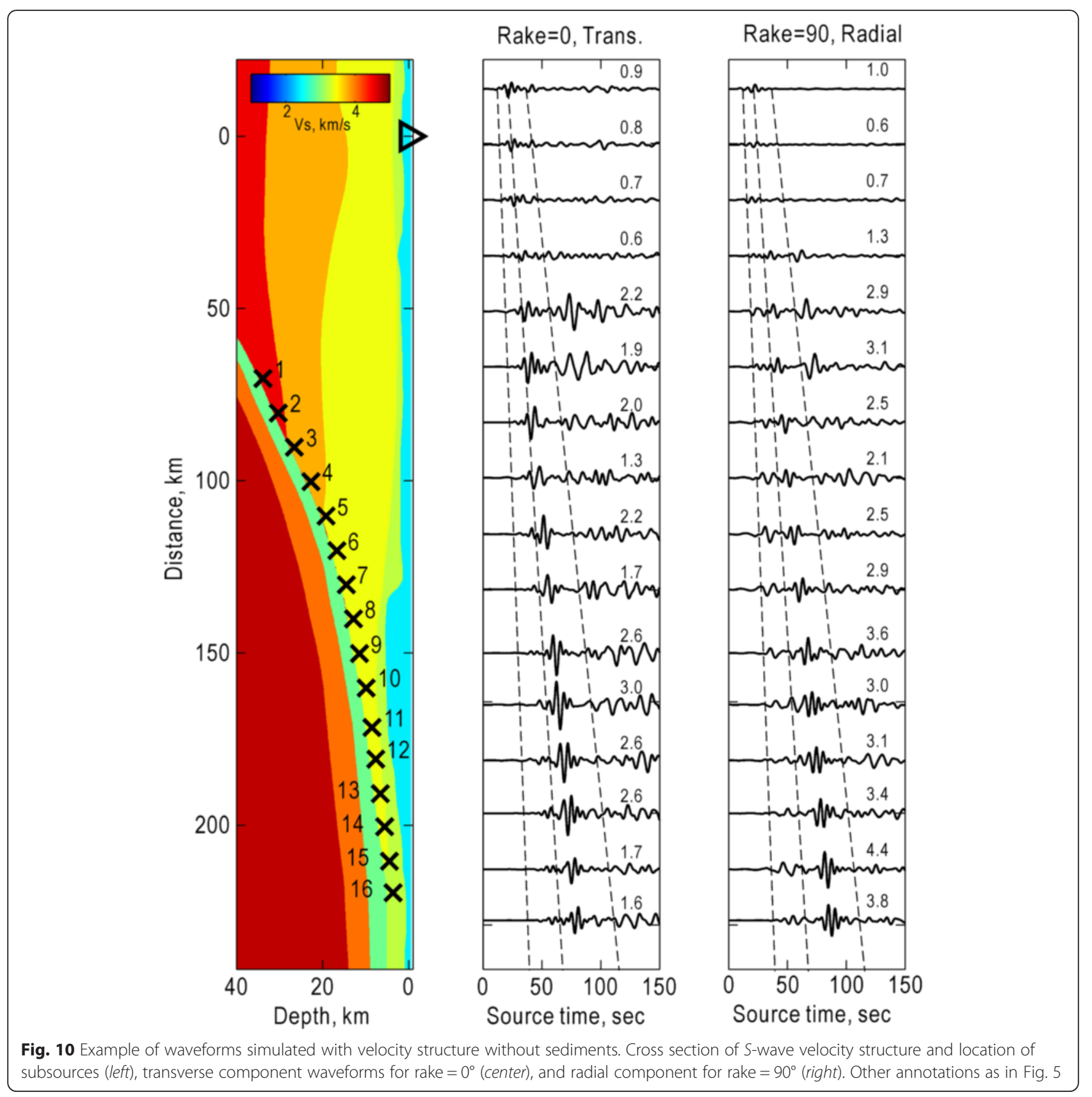

waves) is responsible for the predominantly long-period strong ground motions characteristic of earthquakes in the Osaka basin. This phenomenon may explain the amplification of waves from subsources associated with anomaly 2.

Moreover, Fig. 5 shows that for the radial component for rake $=90^{\circ}$ there are noticeable time delays for the large-amplitude waves from the four shallowest subsources (numbered 13-16 in Fig. 5) for the JIVSM simulations, which were not observed for simulations with the velocity structure without sediments in the accretionary prism (Fig. 10). The time delays, as well as longer durations of the waves, indicate that generation of surface waves in the accretionary prism also increases the amplitudes of waves from subsources in the area of anomaly 3 .

\section{Detailed discussion of effects of seismic potency and seismic impedance of subsource}

One intriguing question remains unexplained: If the effect on GF amplitudes of body-wave propagation from the deep subsources closest to the target site is stronger than elsewhere, why are GF amplitudes there low, even though the effect of the radiation pattern shown in Fig. 6 
is strongest there? To investigate this question, we considered the distribution of subsources among the various layers of the velocity structure model; that is, we determined which of them were within each of the mantle wedge, lower crust, upper crust, and seismic basement layers of the model. Figure 11 shows a result of this analysis superimposed on the simulated distribution of GF amplitudes for the radial component for rake $=90^{\circ}$ (as in Fig. 4b).

This analysis demonstrates that the lower boundary of anomaly 2 corresponds with the boundary between the lower and upper crust. GF amplitudes from subsources in the upper crust are about three times larger than those from subsources in the lower crust. There are two possible causes of the lower GF amplitudes from subsources in the lower crust and mantle: the effect of lower seismic potency at greater depths, as previously discussed, and the effect of waves reflected at the Moho and Conrad discontinuities. Reflection of upward incident waves would decrease GF amplitudes, whereas reflection of downward incident waves would increase GF amplitudes. Because it is difficult to isolate the effect of reflection of long-period waves in a complex $3 \mathrm{D}$ velocity structure, we instead evaluated the effects of properties of the source media. That is, we examined the effects of seismic potency and seismic impedance on GF amplitudes and assumed that wave reflections at the Moho and Conrad discontinuities accounted for all that we could not attribute to seismic potency or seismic impedance.

According to the generally accepted convention for earthquake source modeling, we used the same seismic moment for all subsources. Ben-Zion (2001; see also Aki and Richards 1980 second edition) considered that seismic wave generation in an earthquake source region may be better described by seismic potency, which is defined as the ratio of seismic moment and shear modulus $\left(M_{0} / \mu\right)$. Another effect of source medium is related to changes of seismic impedance, which is the product of density and wave velocity ( $\rho V_{S}$ for $S$-waves, where $\rho$ is density and $V_{S}$ is $S$-wave velocity). During propagation of waves from the source to target site, wave amplitude increases as the square root of the source-to-site impedance ratio. Because $\mu=\rho V_{S}^{2}$, both effects can be described in terms of density and $S$-wave velocity near the source. Aki and Richards (1980; their equation 4.97) combined these and other effects of density and $S$-wave velocity into a single amplification coefficient $(c)$ :

$$
c=1 / V_{S}^{2} \sqrt{V_{S} \cdot V_{S 0} \cdot \rho \cdot \rho_{0}},
$$

where $V_{S}$ and $\rho$ are the $S$-wave velocity and density at the subsource, respectively, and $V_{S 0}$ and $\rho_{0}$ are the $S$ wave velocity and density at the target site, respectively.

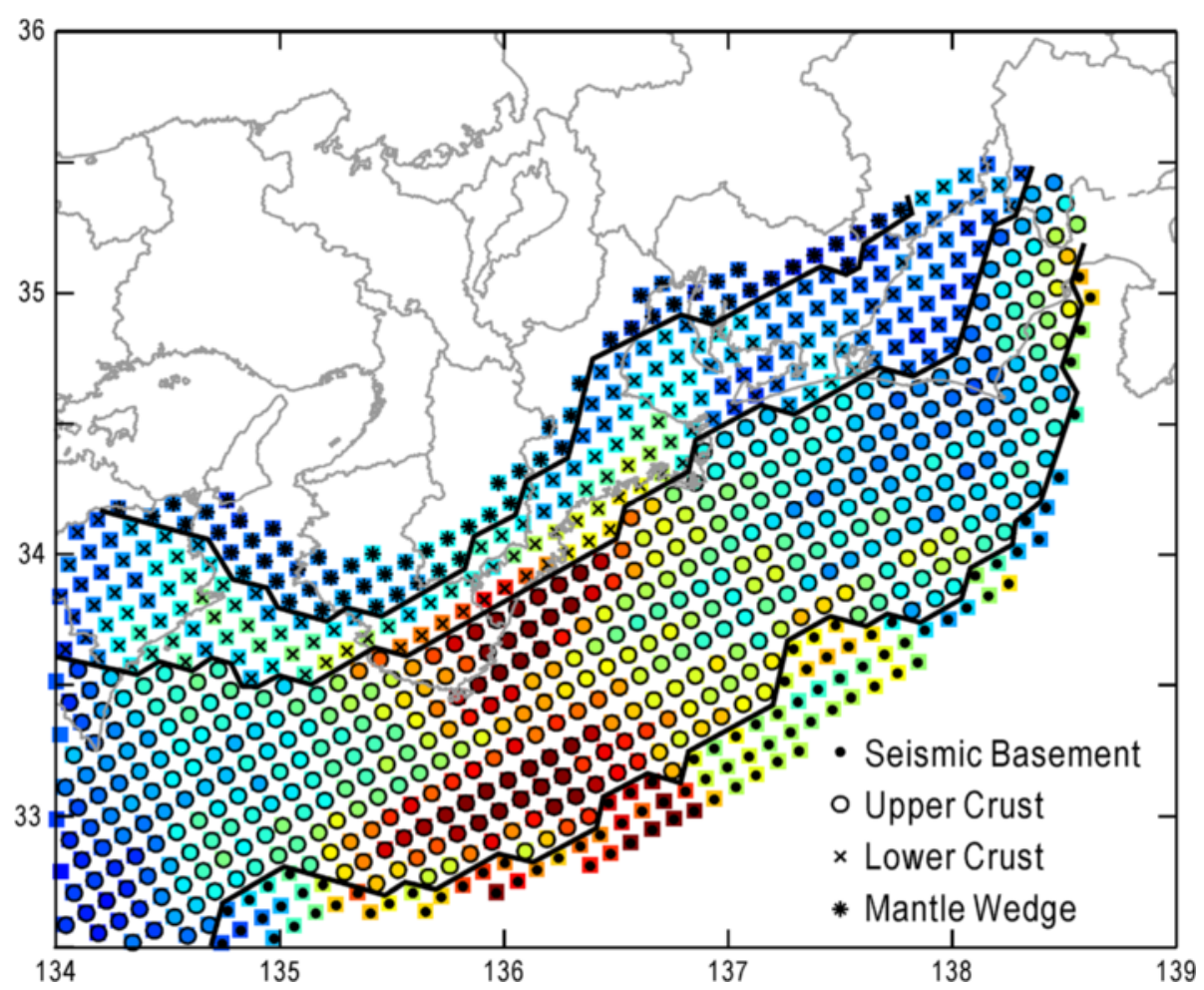

Fig. 11 Distribution of subsources among crustal layers. Colors indicate normalized amplitudes for radial component for rake $=90^{\circ}$ (see Fig. 4b) 
The velocities and densities of the layers of the JIVSM model and values of $c$ calculated for each layer according to Eq. (1) are shown in Table 1.

GF amplitudes for subsources in the upper crust are larger by a factor of 1.33 than those in the lower crust (Table 1), which is smaller than the factor of 3.0 for corresponding GF amplitudes shown in Fig. 11. We assigned the difference (around 2.25) to the combined effect of amplitude losses due to reflection at the Conrad discontinuity of waves coming from subsources below the discontinuity, and amplitude increases due to constructive interference of direct waves and waves reflected from the discontinuity for subsources above it. Thus, in addition to seismic potency, wave reflections at the Conrad discontinuity may contribute to the formation of the lower boundaries of anomalies 1 and 2 .

\section{Analysis of the time delay of peak amplitudes}

We next considered the spatial distribution of the time delay of peak amplitude (peak delay time). Figure 12 shows the distribution of reduced peak delay time for the radial component for rake $=90^{\circ}$, calculated as

$$
T_{\text {red }}=T_{\text {peak }}-R / V_{S}
$$

where $T_{\text {peak }}$ is the peak delay time and $R$ is the hypocentral distance; we assumed $V_{S}=3.4 \mathrm{~km} / \mathrm{s}$, the JIVSM velocity for the upper crust. Figure 12 confirms that the propagation times of peak amplitudes for anomaly 2 are compatible with body $S$-waves, whereas those for anomaly 3 are compatible with the surface waves.

\section{Discussion}

All effects considered above, as well as their influence on GF amplitudes, are compiled in Table 2 for further comparison. Our analysis supposes that effects of source mechanism and accretion prism may be strong for the formation of anomaly 3, effect of basin sediments may be strong for the formation of anomaly 2, while effect of reflection from Conrad discontinuity may be strong for the formation of anomalies 1 and 2 .

Comparison of the locations of previously defined SMGAs (Fig. 1) with the locations of anomalies 1, 2, and

Table 1 S-wave velocities and densities for the JIVSM model and amplification coefficients c calculated according to Eq. (1). We assumed $V_{S 0}=600 \mathrm{~m} / \mathrm{s}$ and $\rho_{0}=2000 \mathrm{~kg} / \mathrm{m}^{3}$ at the target site

\begin{tabular}{llll}
\hline Layer & $V_{\mathrm{s}} \mathrm{m} / \mathrm{s}$ & $\rho, \mathrm{kg} / \mathrm{m}^{3}$ & $\mathrm{c} \times 10^{14}$ \\
\hline Seismic basement & 2900 & 2600 & 3.09 \\
Upper crust & 3400 & 2650 & 2.63 \\
Lower crust & 3800 & 2700 & 1.97 \\
Mantle wedge & 4500 & 2800 & 1.27 \\
\hline
\end{tabular}

3 gives an indication of which of the SMGAs may be primarily responsible for ground motion at our Konohana target site. Simulation parameters for these SMGAs need to be fine-tuned to provide accurate predictions of strong ground motion there.

The velocity model we used for our simulations did not include an oceanic water layer. Inclusion of a water layer and seafloor topography reduces the amplitude of surface waves because of the scattering effect of topography and may also reduce the amplitude of surface Raleigh waves because of the suppression effect of the water mass (Petukhin et al. 2010). Both of these effects may reduce the GF amplitudes of anomaly 3 .

In a near trench area, a simplified fault plane parallel to the subducting plate is assumed in this study. A real fault system consists of deep mega-splay fault (detachment fault) and seaward decollement; both are plateparallel, and the mega-splay fault that is branching to the surface and having a dip angle is considerably larger than assumed here (e.g., Tsuji et al. 2014). Ruptures at subsources on the mega-splay fault would result in large GF amplitudes due to intensive generation of surface waves.

Although the effect of the generation of surface waves in the accretionary prism is considered to be important to explain anomaly 3 , this is a badly constrained part of the velocity structure model. Recently developed network of the ocean-bottom seismometers DONET (e.g., Nakano et al. 2013) should be helpful to improve accretion prism structure model and to validate effect of generation of surface (basin?) waves by direct observation.

It is important to note that the GF anomalies discussed here are specific to the Konohana target site, which lies at the center of the large Osaka basin hosting a megacity. For other megacities, such as Tokyo, Nagoya, and Fukuoka in Kyushu, the distribution of anomalies differs from those presented here. If our conclusions here are valid, GF anomalies relevant to Nagoya would lie east of the anomalies discussed here, those relevant to Hiroshima would be off Shikoku, and those relevant to Fukuoka would be in the Hyuga-Nada region. Tokyo, however, lies in a nodal direction from the megathrust source, so small GF anomalies may be expected there, although the influence of the directivity effect due to rupture propagation is strongest among all megacity cases.

Wave interference within a basin can cause large variations of GF amplitudes that are related to the location of the target site inside the basin, the target period and component orientation of ground motion. Sekiguchi et al. (2008) and Kawabe and Kamae (2008) provide examples of these for the Osaka basin. Direction of wave incidence also affects responses within a 


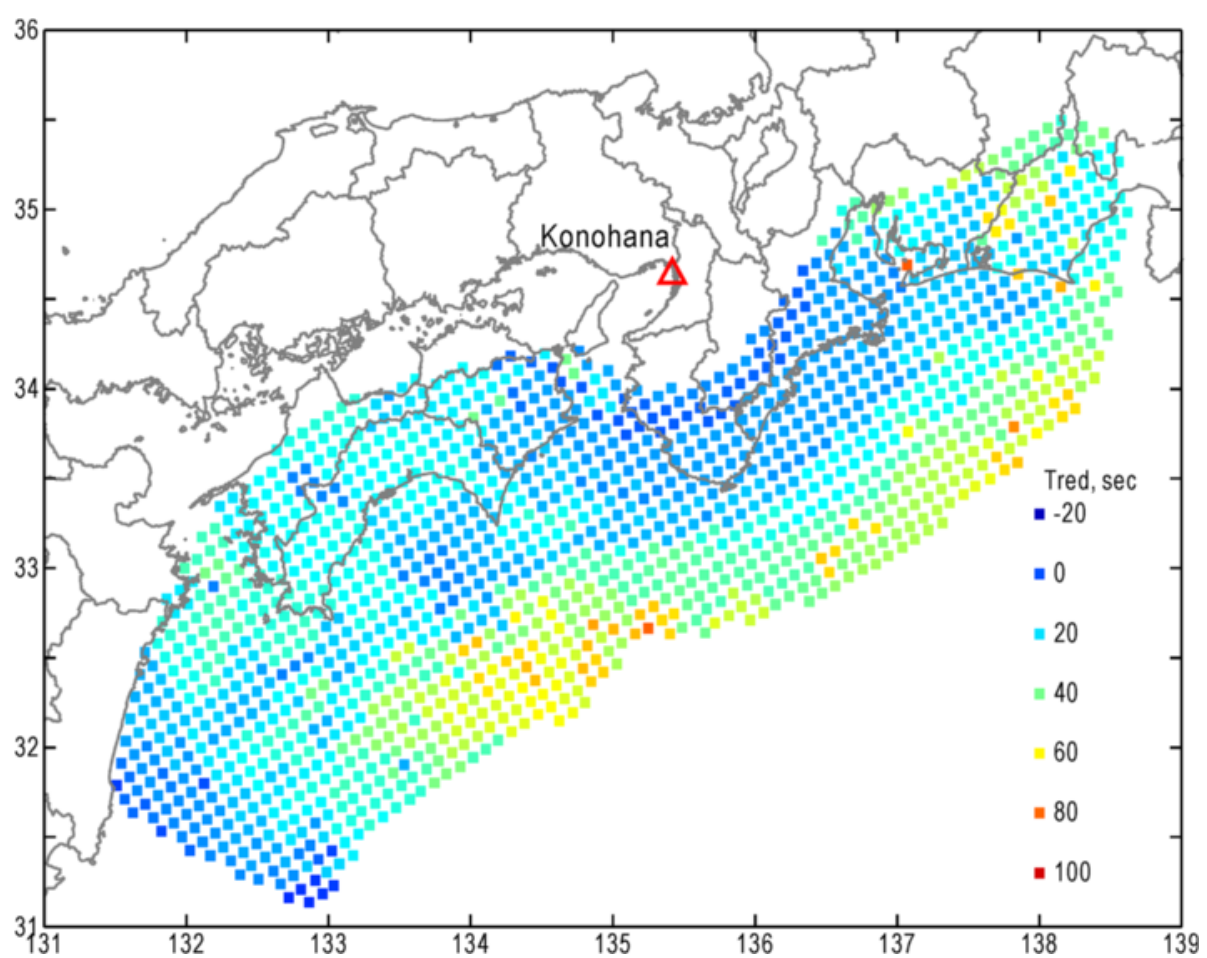

Fig. 12 Analysis of time delay of peak amplitudes. Distribution of peak delay time of peak amplitudes for radial component for rake $=90^{\circ}$ (along dip direction). See text for details of calculation of time delay

basin. For all these reasons, GF amplitudes may differ even for sites that are close together inside the basin.

As concluded above, reflection of waves from deep or shallow subsources at the Moho and Conrad discontinuities has a considerable effect on attenuation or amplification of those waves; this can be attributed in part to the relative simplicity of the JIVSM model, which consists of layers of constant internal velocity and with large impedance contrasts at layer boundaries. For a model such as this, Graves and Pitarka (2010) considered that reflections from the Moho discontinuity make an important contribution to GF amplification because they arrive simultaneously with the direct waves. This was supported during validation of the JIVSM model by Petukhin et al. (2012) and T. Masuda (personal communication) using records of crustal earthquakes; they noted that the amplitudes of waves reflected at the Conrad discontinuity were larger than the observed waves. It may be necessary to revise the structure of the velocity model by introducing velocity gradients within layers and reducing impedance contrasts between them to improve simulations and strong ground-motion predictions.

Table 2 Qualitative comparison of the influences of various factors on generation of anomalies 1, 2, and 3

\begin{tabular}{|c|c|c|c|c|}
\hline \multirow[t]{2}{*}{ Factor } & \multirow[t]{2}{*}{ Effect } & \multicolumn{3}{|c|}{ Level of influence } \\
\hline & & Anomaly 1 & Anomaly 2 & Anomaly 3 \\
\hline Distance & Geometric spreading attenuation & Weak & Weak & Weak \\
\hline Source mechanism & Large amplitudes in lobes of radiation pattern & Medium & Weak & Strong \\
\hline Surface waves & Surface waves generated for shallow subsources & Weak & Weak & Weak \\
\hline Seismic potency & Increase or decrease amplitudes, respectively, for shallow and deep subsources & Medium & Medium & Weak \\
\hline Seismic impedance & Decrease or increase amplitudes, respectively, for shallow and deep subsources & Medium & Medium & Weak \\
\hline Basin sediments & Generation of basin waves & Medium & Strong & Weak \\
\hline Accretionary prism & Generation of surface waves & Weak & Weak & Medium \\
\hline $\begin{array}{l}\text { Reflection from Conrad } \\
\text { discontinuity }\end{array}$ & $\begin{array}{l}\text { Increase or decrease amplitudes for subsources, respectively, above or below } \\
\text { Conrad discontinuity }\end{array}$ & Strong & Strong & Weak \\
\hline
\end{tabular}




\section{Conclusions}

1. We used simulation by the reciprocity method to visualize the distribution of amplitudes of GFs in the Nankai Trough and validated this approach by forward FDM simulation for three point sources in the megathrust earthquake source area. The waveforms of horizontal components for the forward and reciprocal simulations are almost identical.

2. We identified three large GF amplitude anomalies: there were anomalies for both transverse and radial components in an elongated area parallel to the trench just south of the Kii Peninsula (anomalies 1 and 2), and another anomaly for the radial component only, of similar orientation, but closer to the trench (anomaly 3). GF amplitudes in the anomalous areas are two to three times larger than those in surrounding areas.

3. The anomalous simulated GF amplitudes reflect the combined effect of various factors (Table 2). For anomaly 1, the most important factors are source radiation pattern, wave reflection from the Conrad discontinuity, and seismic potency. For anomaly 2, they are the generation of basin waves, wave reflection from the Conrad discontinuity, and seismic potency. For anomaly 3, they are source radiation pattern, seismic potency, and generation of surface waves in the accretionary prism.

4. Areas of anomalous GF amplitude are important for the asperity/SMGA setting of source models for strong motion predictions for megathrust earthquakes. If SMGAs lie within anomalous areas such as those we identified, large slip ruptures originating there would be expected to cause large ground motions.

\footnotetext{
Abbreviations

CDMC: Central Disaster Management Council of Japan; FDM: finite-difference method; GF: Green's function; HERP: The Headquarters for Earthquake Research Promotion; JIVSM: Japan Integrated Velocity Structure Model; SMGA: strong motion generation area.
}

\section{Competing interests}

There are no competing interests to declare.

\section{Authors' contributions}

AP developed software, conducted numerical simulations, and drafted this manuscript. Idea of this study is proposed by HK and KK. KM and MT took part in the interpretation of results. All of the authors carried out theoretical considerations and approved the manuscript.

\section{Acknowledgements}

Discussions with Robert Graves help us to develop the software used in this study. The reviews provided by two anonymous reviewers and comments provided by editor Prof. Hiroshi Takenaka were extremely helpful and led to significant improvements in the quality of the manuscript. The manuscript was also improved by proofreading by Alex Forbes and Andrew Alden from ELSS, Inc.

\section{Author details}

${ }^{1}$ Geo-Research Institute, Otemae 2-1-2, Chuo-ku, Osaka 540-0008, Japan.

${ }^{2}$ Disaster Prevention Research Institute, Kyoto University, Kyoto, Japan.

${ }^{3}$ Research Reactor Institute, Kyoto University, Kyoto, Japan.

Received: 5 March 2015 Accepted: 9 January 2016

Published online: 15 January 2016

\section{References}

Aki K, Richards PG (1980) Quantitative seismology: theory and methods. WH Freeman and Co., San Francisco

Baba T, Ito A, Kaneda Y, Hayakawa T, Furumura T (2006) 3-D seismic wave velocity structures in the Nankai and Japan Trench subduction zones derived from marine seismic surveys. Paper presented at the Japan Geoscience Union Meet, Chiba, 2006, Abst. S111-006.

Ben-Zion Y (2001) On quantification of the earthquake source. Seismol Res Lett 72:151-152

Central Disaster Management Council of Japan (2003) Meeting document: 14th Meeting of the Special Board of Inquiry on Tonankai and Nankai earthquake. http://www.bousai.go.jp/kaigirep/chuobou/senmon/tounankai_nankaijishin/ 14/index.html (in Japanese)

Central Disaster Management Council of Japan (2012) Meeting document: $2^{\text {nd }}$ Review Meeting of the Special Board of Inquiry on Megathrust Earthquake in Nankai Trough. http://www.bousai.go.jp/jishin/nankai/model/ (in Japanese)

Eisner L, Clayton RW (2001) A reciprocity method for multiple-source simulations. Bull Seismol Soc Am 91:553-560

Graves RW (1996) Simulating seismic wave propagation in 3D elastic media using staggered-grid finite differences. Bull Seismol Soc Am 86:1091-1106

Graves R, Pitarka A (2010) Broadband ground-motion simulation using a hybrid approach. Bull Seismol Soc Am 100:2095-2123. doi:10.1785/0120100057

Graves R, Wald D (2001) Resolution analysis of finite fault source inversion using 1D and 3D Green's functions. I Strong motions. J Geophys Res 106:8767-8788

Headquarters for Earthquake Research Promotion (2009) Long Period ground Motion Hazard Map in Japan, 2009 year edition. http://www.jishin.go.jp/ main/chousa/09_choshuki/index.htm (in Japanese)

Headquarters for Earthquake Research Promotion (2013). Evaluations of occurrence potentials or subduction-zone earthquakes, http://www.jishin.go. jp/main/chousa/13may_nankai/index.htm (in Japanese).

Kagawa T, Zhao B, Miyakoshi K, Irikura K (2004) Modeling of 3D basin structures for seismic wave simulations based on available information on the target area: case study of the Osaka basin. Bull Seismol Soc Am 94:1353-1368

Kagawa T, Petukhin A, Koketsu K, Miyake H, Murotani S (2012) Source modeling and long-period ground motion simulation for the 1946 Nankai earthquake. In: Proceedings of the 15th World Conference on Earthquake Engineering, Lisbon, Portugal, 24-28 September, Paper 0806

Kakehi Y (2004) Analysis of the 2001 Geiyo, Japan, earthquake using high-density strong ground motion data: detailed rupture process of a slab earthquake in a medium with a large velocity contrast. J Geophys Res 109:B08306

Kawabe H, Kamae K (2008) Prediction of long-period ground motions from huge subduction earthquakes in Osaka, Japan. J Seismol 12:173-184

Koketsu K, Miyake H, Suzuki H (2012) Japan Integrated Velocity Structure Model Version 1. In: Proceedings of the 15th World Conference on Earthquake Engineering, Lisbon, Portugal, 24-28 September, Paper 1773

Miyake H, Koketsu K (2005) Long-period ground motions from a large offshore earthquake: the case of the 2004 off the Kii peninsula earthquake, Japan. Earth Planets Space 57:203-207

Miyakoshi K, Horike M, Nakamiya R (2013) Long predominant period map and detection of resonant high-rise buildings in the Osaka basin, western Japan. Bull Seismol Soc Am 103:247-257

Morikawa N, Maeda T, Aoi S, Fujiwara H (2013) New Source Models of Nankai Trough Mega-Earthquake and Long-Period Ground Motions caused by them. In: Proceedings of the 41th Symposium of Earthquake Ground Motion, Tokyo, pp 57-64

Nakano M, Nakamura T, Kamiya S, Ohori M, Kaneda Y (2013) Intensive seismic activity around the Nankai trough revealed by DONET ocean-floor seismic observations. Earth Planets Space 65:5-15

Petukhin A, Iwata T, Kagawa T (2010) Study on the effect of the oceanic water layer on strong ground motion simulations. Earth Planets Space 62:621-630

Petukhin A, Kagawa T, Koketsu K, Miyake H, Masuda T, Miyakoshi K (2012) Construction and waveform testing of the crustal and basin structure models 
for southwest Japan. In: Proceedings of the 15th World Conference on Earthquake Engineering, Lisbon, Portugal, 24-28 September, Paper 2789

Pitarka A (1999) 3D elastic finite-difference modeling of seismic motion using staggered-grid with non-uniform spacing. Bull Seismol Soc Am 89:54-68

Poiata N, Miyake H, Koketsu K, Hikima K (2012) Strong-motion and teleseismic waveform inversions for the source process of the 2003 Bam, Iran, Earthquake. Bull Seismol Soc Am 102:1477-1496

Sekiguchi H, Irikura K, Iwata T (2000) Fault geometry at the rupture termination of the 1995 Hyogo-ken Nanbu Earthquake. Bull Seismol Soc Am 90:117-133

Sekiguchi H, Yoshimi M, Horikawa H, Yoshida K, Kunimatsu S, Satake K (2008) Prediction of ground motion in the Osaka sedimentary basin associated with the hypothetical Nankai earthquake. J Seismol 12:185-195

Tsuji T, Ashi J, Ikeda Y (2014) Strike-slip motion of a mega-splay fault system in the Nankai oblique subduction zone. Earth Planets Space 66:120-133

Tsurugi M, Zhao B, Petukhin A, Kagawa T (2006) Strong ground motion prediction in Osaka prefecture due to the Assumed Nankai and Tonankai Earthquake. Chikyu 55:168-175 (in Japanese)

Yamanaka Y, Kikuchi M (2004) Asperity map along the subduction zone in northeastern Japan inferred from regional seismic data. J Geophys Res. doi:10.1029/2003JB002683

Yoshida K, Miyakoshi K, Irikura K (2011) Source process of the 2011 off the Pacific coast of Tohoku Earthquake inferred from waveform inversion with longperiod strong-motion records. Earth Planets Space 63:577-582

\section{Submit your manuscript to a SpringerOpen ${ }^{\odot}$ journal and benefit from:}

- Convenient online submission

- Rigorous peer review

- Immediate publication on acceptance

- Open access: articles freely available online

- High visibility within the field

- Retaining the copyright to your article

Submit your next manuscript at $\gg$ springeropen.com 